Battakhov P.P.

Candidate of Law Sciences, senior research associate of the sector of enterprise and corporate law of Institute of state and law of the Russian Academy of Sciences (IGP RAS)

\title{
ISSUES OF LEGAL REGULATION UNDER RUSSIAN LAW
}

Annotation

In the course of the study, which is carried out as part of this work, a definition of the concept of "social entrepreneurship" will be given, its essence and varieties will be revealed. The focus is on issues that are not sufficiently addressed in existing studies. First of all, we are talking about contractual relations on intellectual property objects in which social entities participate, as well as proposals on how to improve the laws of the Russian Federation in this direction.

Keywords: social entrepreneurship, economy, activity, need, politics, business, enterprise, responsibility

Entrepreneurship is the process by which financial and economic activities are carried out for profit.

Russian entrepreneurship has a long history. Obviously, over the years it has changed significantly, like all other state phenomena, it has adapted to the needs of modern society. In recent years, social entrepreneurship has become increasingly popular, being an independent area. When at the end of the past - at the beginning of this century there was a transition to a postindustrial society, independent directions began to develop in the Russian economy. Entrepreneurship aimed at achieving social benefits is a vivid example of this. Today, this direction is rapidly developing around the world, because new mechanisms and ways that can ensure social policy are urgently needed for the economy. Russian legislation pays attention to social tasks, especially with regard to the development of small and medium-sized businesses and their support in the Russian Federation. In 2019, Federal Law No. 209 was amended [1]. But today it is still necessary to revise a number of articles, in view of the fact that modern society, which is rapidly developing, has new social needs, Federal Law No. 31.07.2020 of 254-Ф3 is an important step towards the approval of the official status of social entrepreneurial activity. This legislative document introduced concepts that have become fundamentally new for the Russian economy. So, officially presented social entrepreneurship and partnership [2].

It should be emphasized that today there is no complete development of the conceptual apparatus of social entrepreneurship, which is due to the recent formalization of it at the legislative level in Russia, as well as its lack in economic literature.

Having analyzed the existing definitions of social entrepreneurship, it can be said that it means a certain mechanism that allows, through entrepreneurial activity, to solve the social problems of society. Social entrepreneurship is an independent intermediary between the state and its population, brings private initiative to the state level. The main goal of a social entrepreneur is to create an effective business model that would eliminate or eliminate imbalances in society as much as possible.

When social entrepreneurship appeared, it will eventually bring the country's economic situation to development, which is explained by the direct impact of the well-being of the population on the country's reputation in the international arena [3]. Having analyzed the legislative activities of the Russian Government, you can see the development of this area. In 2020, social entrepreneurship received legal status and became the official direction of the economy. This is a consequence of the establishment of the registration requirement of the Ministry of Economic Development of the Russian Federation. In addition, social business must be included in the Unified List of Small and Medium-Sized Enterprises of the Russian Federation [4]. It should be emphasized that the conditions for the implementation of this direction contain the first part of Art. 24.1 FZ No. 209-Ф3. 
Today, for the further development of social entrepreneurship in Russia, a number of important problems need to be solved. Many scholars of the economic sphere give different interpretations of this concept. So, based on Civil Law [5], the concept of entrepreneurship should be regarded as an independent activity, the purpose of which is to profit. The regulatory act also contains information that a social entrepreneur works at his own risk.

To reveal this topic as fully as possible, you need to understand the concept of a social enterprise in more detail. According to Russian law, a social enterprise is an independent business entity of small or medium-sized businesses. Responsibility between the parties in the work of a social enterprise is one of the issues that needs to be studied today. It should be emphasized that economic facilities in the Russian Federation that have not fulfilled or are not sufficiently fulfilled obligations should be responsible for this. The exception is situations, the established tasks have not been completed or executed in violation of deadlines, due to force majeure circumstances, for example, natural disasters (third paragraph of Article 401 of the Civil Code of the Russian Federation). This paragraph of Art. 401 of the Civil Code of the Russian Federation, excluding other regulatory acts, is the only basis for determining liability in the conduct of social entrepreneurship. For this direction to develop, it is necessary to make some amendments to the existing laws, which more fully revealed its essence. Therefore, we propose to supplement the first paragraph of Art. 401 of the Civil Code of the Russian Federation [6] that a social enterprise should be responsible exclusively for certain guilt. In other words, enterprises that have been registered in a special register as social should be subject to relaxed sanctions, due to the fact that the main area of their work is the achievement of goals useful to society.

The next aspect, which is of particular importance, is how all business entities will share the profits. In accordance with Russian legislation, dividends are distributed in organizations conducting commercial activities between the founders. Given the specific characteristics of nonprofit organizations, this distribution is excluded. There is no need to confuse two different concepts of "social entrepreneurship" and "social responsibility of entrepreneurship." The fundamental factor of social entrepreneurship is profit for further solving problems of a social nature, in particular, charitable goals, ensuring the protection of the animal world, helping people with disabilities, environmental protection, etc. In other words, social return is important, which ensures comprehensiveness, combined with the profits that are generated in the process.

When an enterprise is registered in the relevant register, it is required to indicate the direction of work, confirm its legal grounds and social significance. It follows that social entrepreneurship in the Russian Federation is recognized as an independent economic entity. This is followed by certain questions, which will be further discussed.

The activities of the social enterprise are aimed at improving the well-being of the country's population. Such enterprises address basic social problems and create effective conditions for people to develop.

To better understand the social enterprise, we can give an example of the construction of social facilities (schools, boarding schools, medical centers, etc.), which allows us to solve problems that exist in society. Based on this, we propose to supplement Federal Law No. 209-Ф3 with a new definition of the concept of "social enterprise." Thus, a social enterprise in the new edition is a legal entity that has been registered in the corresponding status, and also performs social tasks in order to achieve the well-being of the population. In the course of its activity, the company takes risks not only for the state, but also for its own property. This change will provide social entrepreneurs with official status, increase their popularity among the country's population.

Due to the fact that the current legislation does not clearly define the concept of "social entrepreneurship," many citizens do not understand what this direction is. According to statistics, only six about businessmen today are participants in social entrepreneurship, due to ignorance of the main issues in this direction. Due to the fact that there is no clear theoretical base, there are high difficulties for social entrepreneurs. This problem should be solved as quickly as possible, taking into account the fact that this direction is the engine of progress in society. 
It should be noted that the contractual relations of each business entity largely depend on whether it has an organizational and legal form. Practice has shown a number of limitations in this area [7]. Today, the use of intellectual property is one of the most pressing areas in the economic sphere. Contracts are often concluded between commercial and non-commercial organizations, but this does not protect the parties to the process from the fact that certain rights can be used illegally. According to statistics, in different instances of courts, both regional and federal, disputes that arise under such agreements are not uncommon. For example, the uncertain situation with leasing or franchise. It is necessary to dwell in more detail on franchising, because this direction is quite interesting for research. Franchising means the process of transferring to a third party (user) on a paid basis the right to perform a certain type of entrepreneurial activity. To put it simply, the holder of the right to share technology, raw materials, trademarks and other elements of the business model for a certain period of time or indefinitely, which ensures the development of its network and additional profit. Similar obligations that arise between business entities, their conditions and boundaries of action are spelled out in Art. 1027 of the Civil Code of the Russian Federation. This article also states that the contract must comply with the rules on the license agreement, which are contained in the seventh section (fourth part of article 1027 of the Civil Code of the Russian Federation).

Next you need to consider controversial points. For example, the implementation of such a statutory task. The products of a non-profit organization are wheelchairs. This product is regarded as a good for society, but in order to successfully implement it, mass production is required. To this end, an untitled contract may be entered into with a commercial organization. However, Russian laws do not directly provide for this type of contractual relationship. In this regard, general rules apply when concluding such agreements.

In accordance with the Civil Code of the Russian Federation, the conclusion of a franchise agreement is possible only on a reimbursable basis, and a non-profit organization cannot be one party to contractual relations. Thus, in this case, it is impossible to transfer rights to a third party in order to fulfill the plan for serial production of wheelchairs. The following sequence of actions can be suggested:

1. The non-profit organization makes the choice of the main goal: the production of wheelchairs as common goods and services;

2. searching for a non-profit organization to establish mass supplies;

3. entering into an untitled franchise agreement free of charge when all conditions have been agreed.

Thanks to this structure of transfer of rights, it becomes possible to realize a good for society. At the same time, existing laws will not be violated. It will also attract more entrepreneurs to social entrepreneurship.

he pandemic of coronavirus infection is the most acute problem that has affected all spheres of life this year. So, for subjects of Russia there is a shortage of volunteers who voluntarily helped the population, for example, delivered products. To solve the problem, social entrepreneurs could be involved. To date, assistance to solve social problems by the state is a sought-after area, it is for this reason that it will be beneficial for each side if this area of activity is formalized at the legislative level.

The refusal to liquidate organizations conducting commercial activities that, due to selfisolation, could not work, is another aspect of supporting the well-being of the population. You can save work centers if the company changes its status. Thanks to such a reorganization, it is possible to attract personnel to social entrepreneurship. In turn, this will increase the level of wellbeing of the country's population.

Based on the above, we can say that with the development of society, new directions of activity of economic entities, in particular, social entrepreneurship, appear and develop. If entrepreneurs are involved in this area, the well-being of the whole country will significantly increase, as a result, this will positively affect the reputation of the Russian Federation in the world community. It should be emphasized that today there are no single legislative documents 
that regulate relations in this area, so there are many controversial issues. Therefore, it is extremely necessary to develop the Federal Law on Social Entrepreneurship, to conduct theoretical studies of this industry.

\section{References}

1. Civil Code of the Russian Federation//NWRF. December 5, 1994g., No.32. Article. 3301.

2. Lysenko V.V. Social entrepreneurship as a new form civil society/business//Constitutional and municipal law. 2016. № 10. C. 43-47.

3. Federal Law of July 24, 2007 No. 209-Ф3 "On the Development of Small and medium-sized enterprises in the Russian Federation "//NWRF. July 302007 No. 31. Article. 4006.

4. Chistov L.M. Theory of effective management of socio-economic systems. The basis of economic science. 2nd ed., Specified. and additional - St. Petersburg: Asterion, 2009.

5. Our Future Foundation begins certification of Russian social enterprises//URL: https://clck.ru/SVFrN 10.10.2018.

6. Federal Law of 12.01.1996 No. 7-Ф3 "On Non-Profit organizations "(ed. From 02.05.2015).

7. Battakhov P.P. Social entrepreneurship in Russia: some Legal Issues//" Labour Law Issues "No.

6. C. $17-23$ 